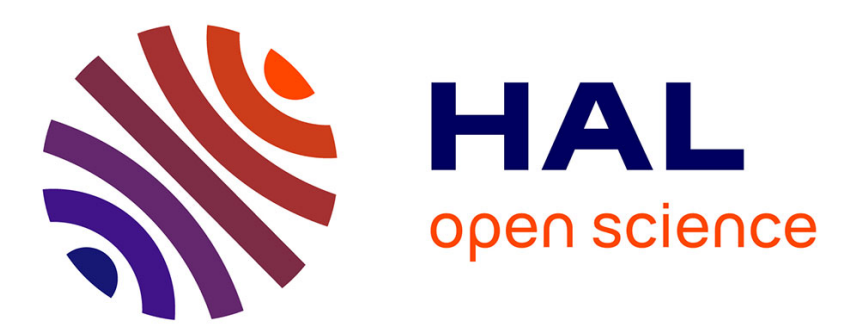

\title{
Electrochimica Acta Sulfonated polyphenyl ether by electropolymerization
}

Hongying Hou, Florence Vacandio, Maria Luisa Di Vona, Philippe Knauth

\section{To cite this version:}

Hongying Hou, Florence Vacandio, Maria Luisa Di Vona, Philippe Knauth. Electrochimica Acta Sulfonated polyphenyl ether by electropolymerization. Electrochimica Acta, 2012, 81 (3), pp.58 - 63. 10.1016/j.electacta.2012.07.082 . hal-02656753

\section{HAL Id: hal-02656753 https://hal-amu.archives-ouvertes.fr/hal-02656753}

Submitted on 5 Jun 2020

HAL is a multi-disciplinary open access archive for the deposit and dissemination of scientific research documents, whether they are published or not. The documents may come from teaching and research institutions in France or abroad, or from public or private research centers.
L'archive ouverte pluridisciplinaire HAL, est destinée au dépôt et à la diffusion de documents scientifiques de niveau recherche, publiés ou non, émanant des établissements d'enseignement et de recherche français ou étrangers, des laboratoires publics ou privés. 


\title{
Sulfonated polyphenyl ether by electropolymerization
}

\author{
Hongying Hou ${ }^{\mathrm{a}, \mathrm{c}}$, Florence Vacandio ${ }^{\mathrm{a}}$, Maria Luisa Di Vona ${ }^{\mathrm{b}}$, Philippe Knauth ${ }^{\mathrm{a}, *}$
}

a Aix Marseille Univ. - CNRS, Laboratoire Chimie Provence (UMR 6264), Centre Saint Jérôme, F-13397 Marseille Cedex 20, France

${ }^{\mathrm{b}}$ Univ. Roma Tor Vergata, Dip. Scienze e Tecnologie Chimiche, 00133 Roma, Italy

${ }^{\mathrm{c}}$ Faculty of Material Science and Engineering, Kunming University of Science and Technology, Kunming 650093, China

\section{A B S T R A C T}

Electropolymerization of sulfonated phenol was for the first time achieved and studied by cyclic voltam-metry (CV) and chronoamperometry on stainless steel substrates. The obtained sulfonated polyphenyl ether was characterized in terms of impedance spectroscopy, nuclear magnetic resonance (NMR), energy dispersive X-ray analysis (EDX), X-ray diffraction (XRD) and Fourier-Transform Infrared (FTIR) spec-troscopy. Dense films of micrometer thickness can be obtained; the proton conductivity is about $3 \mathrm{mS} / \mathrm{cm}$ at room temperature.

\section{Keywords:}

Polymer electrolyte

Electropolymerization

Sulfonated aromatic polymer

Proton conductivity

\section{Introduction}

Electropolymerization is a process where a monomer is polymerized on a conductive or semi-conductive substrate by application of an electrical voltage or current [1-5]. Phenol and its derivatives are aromatic molecules that can be easily polymerized giving various substituted polyphenyl ethers, including poly(phenylene) oxide. The electropolymerization of phenol and its derivatives has been investigated for amperometric and potentiometric sensor applications [6], highly resistive anti-corrosion coatings for metals [7] as well as for domestic or industrial waste water treatment [8]. Electropolymerization can be performed in acid or basic medium on different substrates, including Pt [9], Au [10], stainless steel [11], Cu [12], or various graphite carbon electrodes [13-15]. The mechanism is generally assumed to begin with the formation of the unstable phenoxy radical. This radical may be further oxidized or coupled to form a neutral dimer or a dimeric radical by attacking another molecule. The neutral or radical dimer may be further oxidized resulting in the formation of oligomers or polymers [9]. In the case of insulating polyphenyl ether (PPE), the electropolymerization is self-limited, resulting in very thin adherent PPE films, because insoluble high molecular weight PPE blocks the access to the electrode surface and thus the subsequent electrooxidation of phenol, leading to a very rapid current decrease after the first cyclovoltammetry (CV) cycle. Some attempts have been made by modifying the electrode [16,17] and optimizing the experimental parameters [18].

The introduction of sulfonic acid groups in the aromatic rings may lead to proton-conducting polyphenyl ethers that would be useful for fuel cell applications and other electrochemical devices [19-21]. The increasing demand for various portable electronic appliances, such as cell phones, laptop computers, digital cameras, embedded monitors, autonomous sensors, clinic and diagnostic test devices has stimulated the development of micro-sized power sources, including micro-fuel cells. The electropolymerization technique may be a way to obtain micro-sized membranes for fuel cells. However, the functionalization of PPE with sulfonic acid groups has not been achieved yet. There are well-known preparation techniques for sulfonated aromatic polymer membranes using sulfonation of aromatic polymers by electrophilic aromatic substitution followed by film casting. However, these are time-consuming processes, including a long washing step after sulfonation and the evaporation of solvent by thermal treatment after the membrane casting. The electrochemical deposition of a thin polymer film can be substantially faster and less expensive. Furthermore, the possibility of conformal electrodeposition allows realizing even complicated film shapes for example on nanostructured electrodes or electrode supports. To fully profit from these advantages, it is however necessary to develop a one-step electrodeposition process from a single precursor solution without additional steps.

In this work, the electropolymerization of a sulfonated phenol monomer on stainless steel substrates was explored by cyclic voltammetry (CV) and chronoamperometry and the synthesized polymer film was characterized in terms of 
electrochemical impedance spectroscopy (EIS), nuclear magnetic resonance (NMR), energy dispersive X-ray analysis (EDX), X-ray diffraction (XRD) and Fourier-Transform Infrared spectroscopy (FTIR).

\section{Experimental}

\subsection{Materials}

Phenol (Sigma-Aldrich) and concentrated sulfuric acid (98\%, Fisher Science) were used as received without further purification. Sulfonated phenol was prepared by the following procedure: $4.7 \mathrm{~g}$ phenol $(0.05 \mathrm{~mol})$ was dissolved in concentrated sulphuric acid ( $10 \mathrm{ml}$, about $0.2 \mathrm{~mol}$ ) and kept under stirring at room temperature for $3 \mathrm{~h}$. The obtained solution was diluted to $1 \mathrm{~L}$ with pure water.

\subsection{Electropolymerization}

The electropolymerization was studied by cyclic voltammetry (CV) and chronoamperometry in a conventional three-electrode cell with a stainless steel working electrode (304 L, effective area: $0.28 \mathrm{~cm}^{2}$ ), a platinum sheet as counter electrode and saturated $\mathrm{Ag} / \mathrm{AgCl}$ as reference electrode, respectively. The stainless steel electrode remained inert under the experimental conditions. A potentiostat/galvanostat (EG\&G PARSTAT 2273) was used for all electrochemical experiments. Impedance spectra of the polymer were measured from $100 \mathrm{mHz}$ to $100 \mathrm{kHz}$ with an oscillating voltage amplitude of $10 \mathrm{mV}$. All experiments were carried out at room temperature and atmosphere. The obtained polymer membranes were rinsed with ultra pure water prior to subsequent characterization in order to remove the electrolyte. For comparison, polyphenyl ether films were obtained by electrodeposition of phenol in $\mathrm{Na}_{2} \mathrm{SO}_{4}$ supporting electrolyte.

\subsection{Structural characterization}

${ }^{1} \mathrm{H}$ NMR spectra were recorded with a Bruker Avance 400 spectrometer operating at $400.13 \mathrm{MHz}$. Chemical shifts (ppm) are referenced to tetramethylsilane (TMS). DMSO-d6 was used as solvent for ${ }^{1} \mathrm{H}$ spectra of sulfonated polyphenyl ether. $\mathrm{D}_{2} \mathrm{O}$ was used as external lock to analyze spectra of the $\mathrm{H}_{2} \mathrm{SO}_{4}$ precursor solution of sulfonated phenol.

XRD patterns were obtained at room temperature with a Siemens D5000 diffractometer with $\mathrm{CuK \alpha}$ radiation $(\lambda=0.15406 \mathrm{~nm})$. The scan range was from $5^{\circ}$ to $25^{\circ}$ and the scan rate was $0.3^{\circ} / \mathrm{min}$.

The morphology and EDX spectrum of the polymer were investigated with a PHILIPS XL-3OFEG Scanning Electron Microscope (SEM). FTIR analyses were performed in transmission mode from 4000 to $400 \mathrm{~cm}^{-1}$ wavenumber with a Bruker Equinox $55 \mathrm{spec}-$ trometer.

\section{Results and discussion}

\subsection{Electropolymerization by CV scanning}

Fig. 1 shows CV curves ( $1-5$ cycles) during the electropolymerization of sulfonated phenol in acidic medium on stainless steel electrodes within a voltage window of $0.7-1.4 \mathrm{~V}$ (all potentials are given vs. a saturated $\mathrm{Ag} / \mathrm{AgCl}$ reference electrode). A welldefined current peak at about $1.15 \mathrm{~V}$ was observed in the first cycle, corresponding to the electro-oxidation of sulfonated phenol on the stainless steel surface. No reduction peak can be observed during negative CV scanning, implying that the oxidation of sulfonated phenol is irreversible. Compared with the electro-oxidation

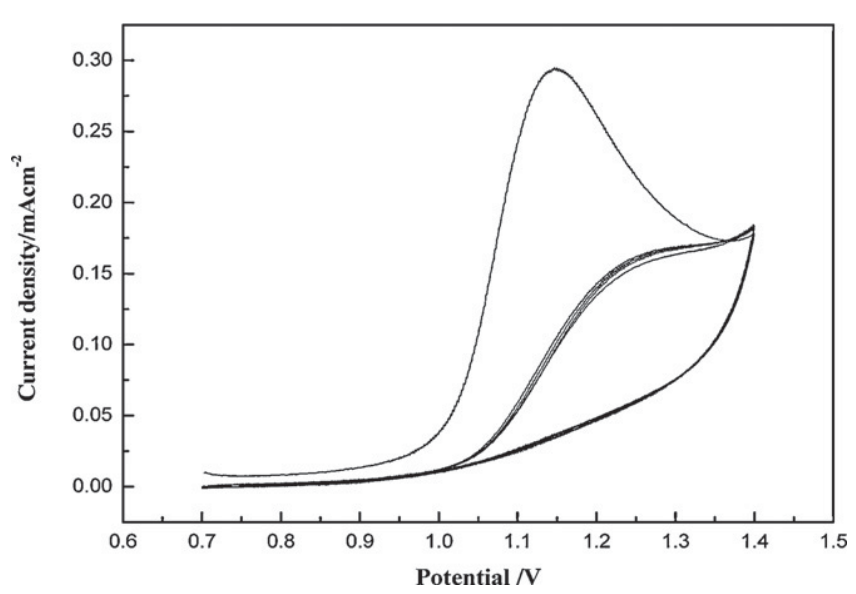

Fig. 1. CV curves (5 cycles) of the electropolymerization of sulfonated phenol on a stainless steel electrode (scanning rate: $20 \mathrm{mV} / \mathrm{s}$, potential vs. saturated $\mathrm{Ag} / \mathrm{AgCl}$ ).

voltage of pristine phenol at about $1.45 \mathrm{~V}$ in nearly neutral medium [22], a significant shift to lower voltage occurred, implying an easier and less energy-consuming electropolymerization of sulfonated phenol. In the second cycle, the peak current decreases by $45 \%$ and the corresponding voltage is shifted in the anodic direction to about 1.25 V. As mentioned above, electro-oxidation of phenol and other phenolic compounds always produces a very rapid decrease of the current after the first cycle, due to formation of a low conductivity film [23-25]. In the following cycles, the CV curves are reproducible, both the current peak and voltage remained constant without further decrease. The voltage remains below the anodic decomposition voltage of water, where oxygen evolution occurs. The proton conductivity (see below) reduces the insulating nature of the electropolymerized film and allows further electropolymerization. When the anodic potential is above $1.8 \mathrm{~V}$, the passivity phenomenon disappears and the iron electrode is quickly oxidized [26].

\subsection{Electropolymerization study by chronoamperometry}

From CV curves in Fig. 1, the electropolymerization of sulfonated phenol occurred at about $1.25 \mathrm{~V}$ after the first cycle; therefore, the constant voltage was set at $1.25 \mathrm{~V}$ for the electropolymerization study of sulfonated phenol by chronoamperometry, as shown in Fig. 2a. The initial abrupt current decrease, due to formation of a high resistance coating on the metal substrate, was followed by a continuous slow current decrease until 3600 s. This part of the curve between 800 and $3000 \mathrm{~s}$ can be described by a square root time dependence, in agreement with a diffusion-limited growth process (Fig. 2b).

According to the generally accepted electropolymerization mechanism of phenol (Scheme 1), the anodic growth occurs through one-electron transfer to phenol (in acidic solution) to give free radicals which then undergo $\mathrm{C}-\mathrm{O}$ coupling, while limiting the direct oxidation reaction from phenol to quinone [26]. The resulting dimers are further oxidized, leading to high molecular weight polymers after several steps. Considering that a part of phenol is not sulfonated in the precursor solution (see Section 3.5), non-sulfonated phenol radicals also take part in the electropolymerization.

The charge transfer occurs at the polymer-electrode interface, given that the polymer is an electronic insulator. To sustain polymer growth, monomers have to diffuse through the polymer layer, which thickness increases with time. After the early stage of growth, the current is thus determined by the monomer diffusion through the polymer film. If the sulfonated phenol concentration at 
<smiles>O=S(=O)(O)c1ccccc1O</smiles>

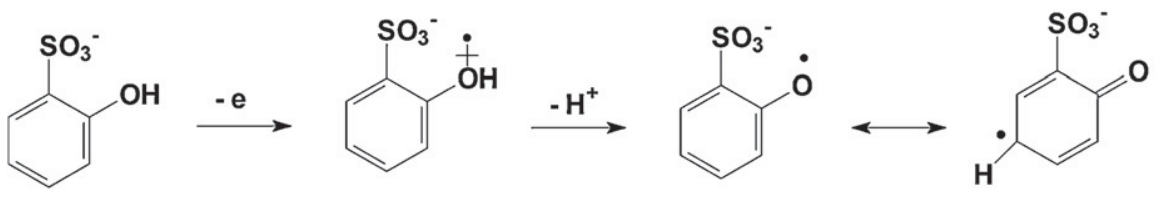<smiles>COS(=O)(=O)c1ccccc1Oc1ccccc1S(=O)(=O)Oc1ccc(O)c(S(=O)(=O)O[Na])c1</smiles>

Scheme 1. Proposed mechanism for the electropolymerization of sulfonated phenol. For simplicity only pathways starting from $o$-hydroxybenzenesulfonic acid are reported.

the electrode surface is taken as 0 , the instantaneous current density $i$ of potentiostatic electrodeposition is given by Eq. (4), derived from the first Fick law [27]:

$i=\frac{d Q}{d t} \cdot \frac{1}{A}=\frac{F D c}{d}$

Here, $Q$ is the charge, $A$ the electrode area, $c$ is the concentration of sulfonated phenol in the precursor solution and $D$ the diffusion coefficient of the monomer in the polymer layer. According to the growth mechanism (Scheme 1), one electron corresponds to one
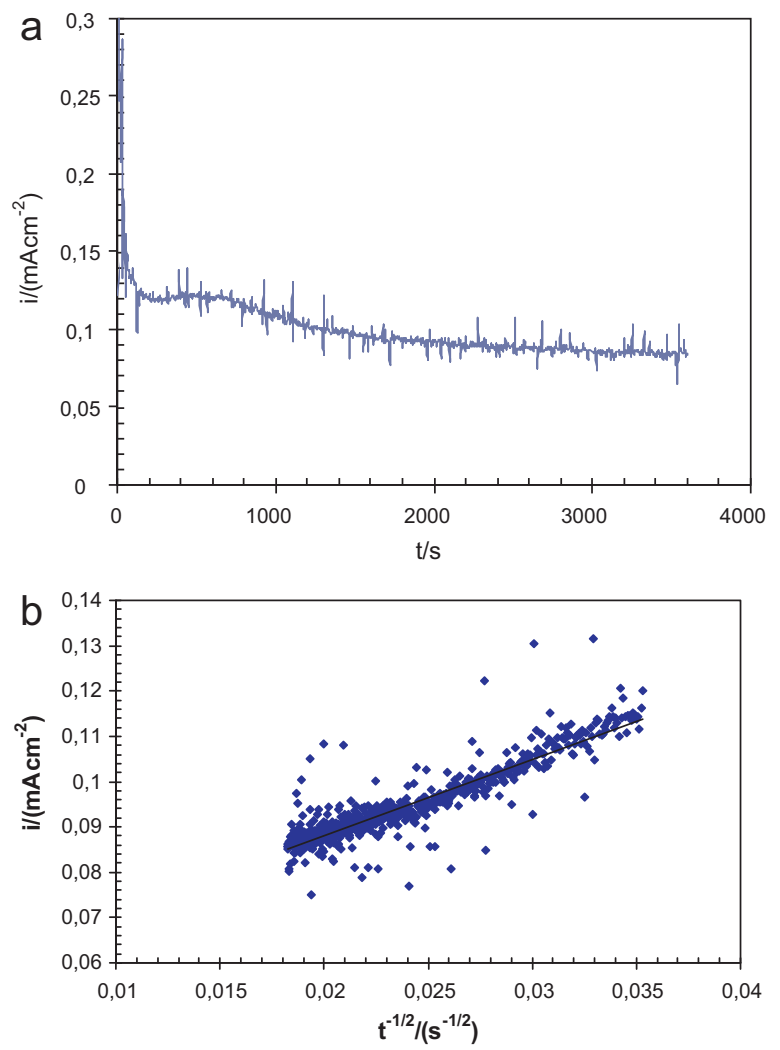

Fig. 2. (a) Typical chronoamperometry curve of the electropolymerization of sulfonated polyphenol on a stainless steel electrode. (b) Diffusion-limited polymer growth shown by the typical square root time dependence of current $i=f\left(t^{-1 / 2}\right)$. aryl ring $(n=1)$ [26]. Assuming that the current efficiency is $100 \%$, like in the case of polyphenyl ether [27], the thickness of the polymer layer $d$ formed at the time $t$ can be expressed as function of the charge $Q$ according to Faraday's law:

$d=\frac{Q M}{F \rho A}$

$\rho$ is the density of the polymer, assumed to be $1 \mathrm{~g} / \mathrm{cm}^{3}$, given that the density of PPE was reported to be $1.0 \mathrm{~g} / \mathrm{cm}^{3}$ [27]. $M$ is the molar mass of sulfonated phenol. An average monomer molar mass of $158 \mathrm{~g} / \mathrm{mol}$ is used, corresponding to a sulfonation degree of $80 \%$ from NMR. Insertion of Eq. (5) into Eq. (4) and integration leads to the charge-time relation:

$Q=F A\left(\frac{2 \rho D c t}{M}\right)^{1 / 2}$

The derivation of this equation gives finally the current density-time relationship:

$i=F\left(\frac{\rho D c}{M t}\right)^{1 / 2}$

This relation can be used to determine the diffusion coefficient $D$ from the slope of the straight line $i=f\left(t^{-1 / 2}\right)$ (Fig. 2b): $D=7 \times 10^{-10} \mathrm{~cm}^{2} / \mathrm{s}$. Considering that the diffusion coefficient of phenol in a polyphenyl ether matrix is about $10^{-8} \mathrm{~cm}^{2} / \mathrm{s}$ [27] and that sulfonated phenol is more bulky and diffuses more slowly, this diffusion coefficient seems quite consistent.

The total electrical charge $(Q)$ of $358 \mathrm{mC}$ for the electropolymerization of Fig. 2 a can be obtained by integrating the $i-t$ curve area. The polymer thickness can be calculated to be $20.9 \mu \mathrm{m}$ using Eq. (5).

\subsection{EDX analysis of sulfonated polyphenyl ether}

In order to evaluate the functionalization of PPE by sulfonic acid groups, EDX spectra of the polymer-covered stainless steel electrodes (thickness about $1 \mu \mathrm{m}$ ) were collected and compared with those of uncovered electrodes as shown in Fig. 3. The EDX spectrum of sulfonated PPE on steel electrodes presents strong signals of $\mathrm{C}, \mathrm{O}$ and $\mathrm{S}$ from polymer chains and sulfonic acid groups besides the signals of $\mathrm{Fe}, \mathrm{Cr}, \mathrm{Ni}$ and $\mathrm{Si}$ from the stainless steel. The elements of the stainless steel substrate can still be observed given that the thickness of the polymer layer is in the micrometer range 

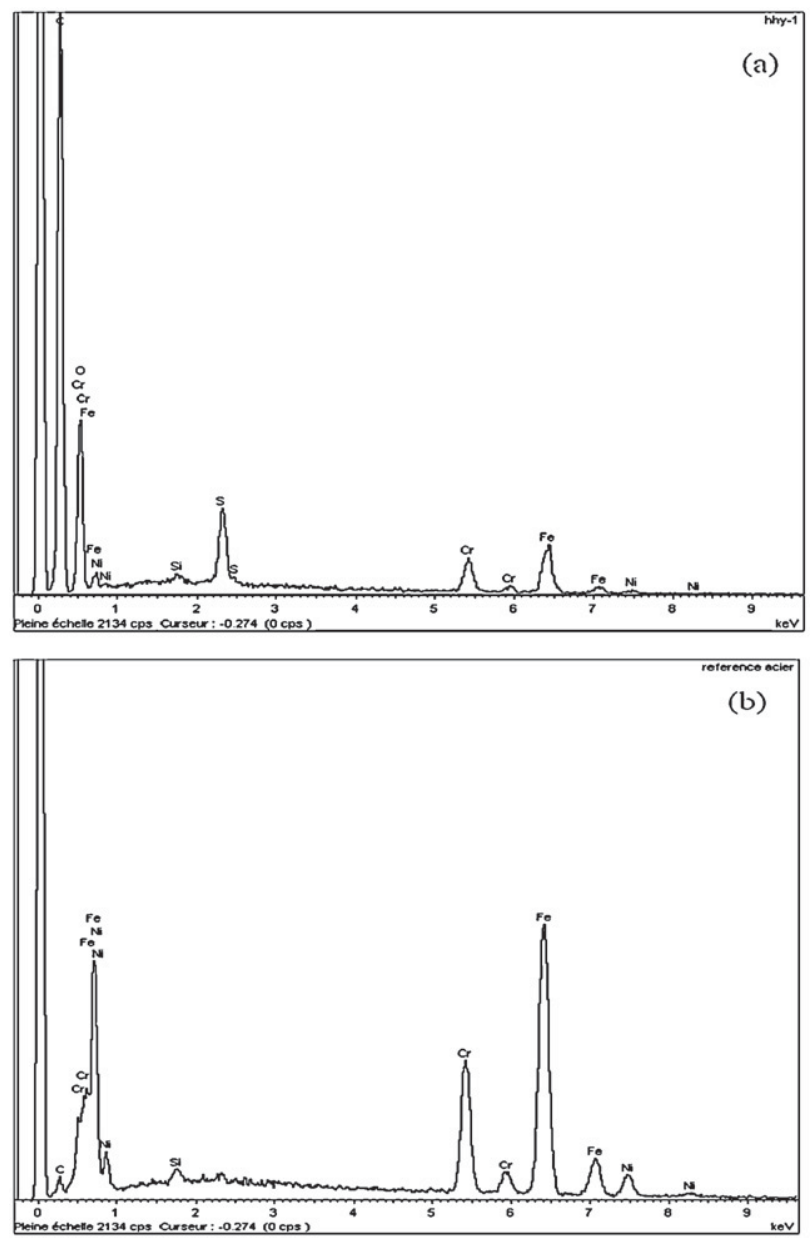

Fig. 3. EDX spectra of (a) sulfonated polyphenyl ether on a stainless steel electrode, and (b) the uncovered stainless steel electrode.

and considering the typical penetration depth of X-rays in solid matter.

\subsection{XRD pattern of sulfonated polyphenyl ether}

Fig. 4 shows a typical XRD pattern of sulfonated PPE. A strong peak at $2 \theta=8.5^{\circ}$ and three weak peaks at $2 \theta=12^{\circ}, 14.5^{\circ}$ and $21.7^{\circ}$ can be observed, which can be attributed to the PPE matrix according to the literature [28]. One can estimate that the broad peak at $8.5^{\circ}$ is a superposition of unsubstituted and sulfonated polyphenyl ether. Compared with the XRD spectrum of PPE powder, the peak at $2 \theta=8.5^{\circ}$ is shifted to lower angles, meaning a larger interplane distance according to Bragg's law, due to the presence of sulfonic acid groups. The introduction of hydrophilic sulfonic acid groups changes the arrangement of macromolecular chains within the polyphenyl ether matrix and reduces its degree of crystallinity, as is well known from other sulfonated aromatic polymers. In addition, the difference of the sample shape between the powder in literature and the membrane in this work is also responsible for this broadening [29].

\subsection{NMR analysis}

The ${ }^{1} \mathrm{H}$ NMR spectrum of the precursor solution is shown in Fig. 5a. The spectrum reveals a mixture of phenol (about 20\%), ophenolsulfonic acid (about 20\%) and p-phenolsulfonic acid (about $60 \%$ ), corresponding to a degree of sulfonation of $80 \%$. Under kinetic control in the presence of concentrated sulfuric acid at room

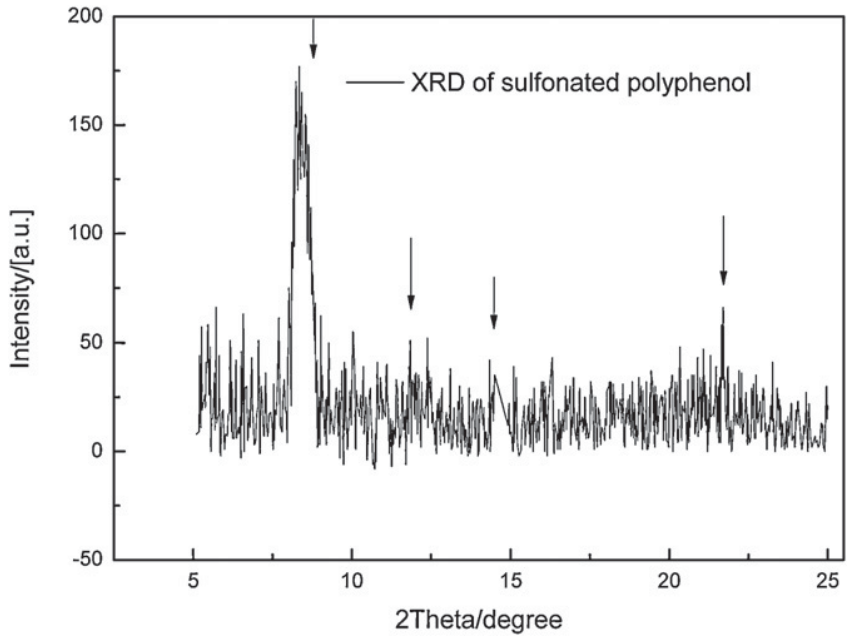

Fig. 4. XRD pattern of sulfonated polyphenyl ether on a steel electrode. The arrows indicate peak positions from Ref. [28].

temperature, the ortho form is formed preferentially and under thermodynamic control the para form is preferred; in our case, the presence of water in the reaction medium leads to formation of both isomers. The peaks of aromatic protons of phenol are situated at $6.7,7.1$ and $7.6 \mathrm{ppm}$. The signals assigned to the aromatic hydrogen atoms at the ortho position to the electron-withdrawing $-\mathrm{SO}_{3} \mathrm{H}$ groups are situated at 6.9 and $7.6 \mathrm{ppm}$. The characteristic doublets of para-phenolsulfonic acid appear at 6.75 and $7.5 \mathrm{ppm}$. The spectrum of the polymer (Fig. 5b) shows an extended polymerization due to the large number of unresolved peaks. They offer all

(a)
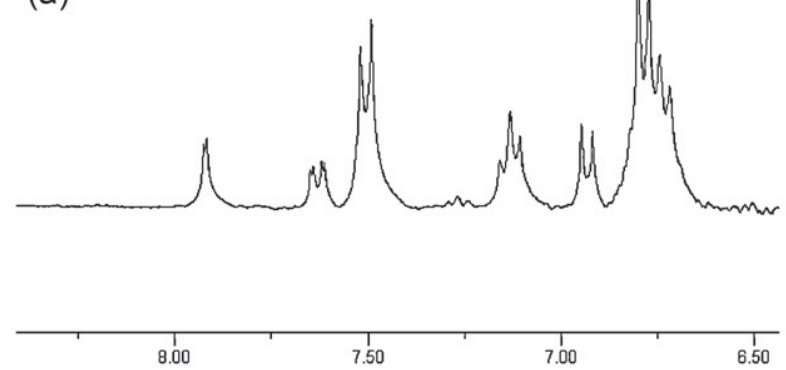

(b)<smiles>O=C1OC2CCC(O)C1CC2</smiles>
○

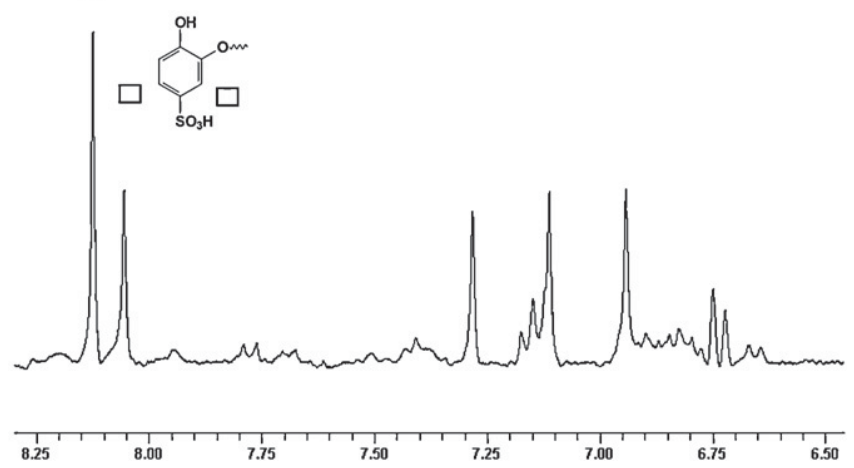

Fig. 5. (a) NMR spectrum of the precursor solution of sulfonated phenol in aqueous $\mathrm{H}_{2} \mathrm{SO}_{4}$. (b) NMR spectrum of sulfonated polyphenyl ether in DMSO. 


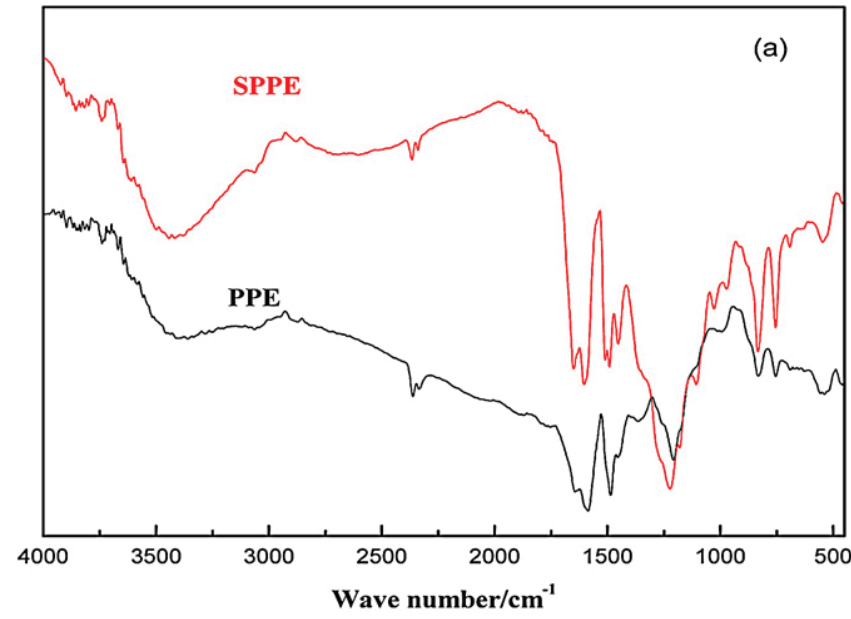

(b)

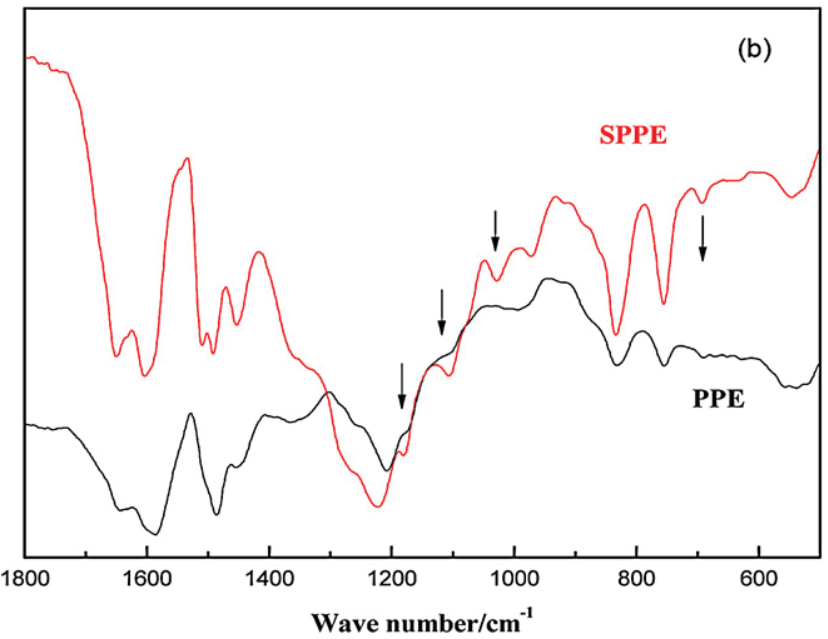

Fig. 6. (a) FTIR spectra of polyphenyl ether (PPE) and sulfonated polyphenyl ether (SPPE) and (b) zoom in the fingerprint region.

information about the position of $-\mathrm{SO}_{3} \mathrm{H}$ groups adjacent to ether bonds [30-32]. The singlet peaks between $7.1 \mathrm{ppm}$ and $7.8 \mathrm{ppm}$ can be assigned to isolated hydrogen atoms on the aromatic ring bearing $-\mathrm{SO}_{3} \mathrm{H}$ groups in ortho- and para-position, indicating that the polymerization occurs in the free activated positions.

\subsection{FTIR spectra of sulfonated polyphenyl ether and polyphenyl ether}

FTIR spectra between $4000 \mathrm{~cm}^{-1}$ and $500 \mathrm{~cm}^{-1}$ of pristine and sulfonated PPE on steel electrodes are shown in Fig. 6(a). For more clarity, the signal-rich fingerprint region between $2000 \mathrm{~cm}^{-1}$ and $500 \mathrm{~cm}^{-1}$ was enlarged as shown in Fig. 6(b). The corresponding peak attributions are listed in Table 1 . In the case of polyphenyl ether, a broad peak centered at $3400 \mathrm{~cm}^{-1}$ is corresponding to $\mathrm{O}-\mathrm{H}$ stretching vibration from the ends of polyphenol chain and the presence of water. The peaks at $1648 \mathrm{~cm}^{-1}, 1590 \mathrm{~cm}^{-1}, 1488 \mathrm{~cm}^{-1}$ and $1450 \mathrm{~cm}^{-1}$ can be attributed to aromatic C $-\mathrm{C}$ stretching vibrations [22]. The strong peak at $1220 \mathrm{~cm}^{-1}$ is due to $\mathrm{Ph}-\mathrm{O}-\mathrm{Ph}$ stretching of aromatic ether chains [33], implying chain propagation during the electropolymerization of phenol. The peaks at $834 \mathrm{~cm}^{-1}, 754 \mathrm{~cm}^{-1}$, and $545 \mathrm{~cm}^{-1}$ correspond to $\mathrm{C}-\mathrm{H}$ bond vibrations. As for sulfonated PPE, beside the peaks mentioned above, additional peaks appeared between $1200 \mathrm{~cm}^{-1}$ and $600 \mathrm{~cm}^{-1}$. According to the literature [30,34-37], these peaks can be assigned to the symmetric stretching vibrations of sulfonic acid groups and $\mathrm{C}-\mathrm{S}$ bonds, respectively. The absence of the peak at $1700 \mathrm{~cm}^{-1}$
Table 1

Peak assignation of FTIR spectra of polyphenyl ether and sulfonated polypheny ether.

\begin{tabular}{ll}
\hline Wave number $\left(\mathrm{cm}^{-1}\right)$ & Chemical bond \\
\hline 3340 & O-H stretching vibration \\
$1648 ; 1590 ; 1488 ; 1450$ & Aromatic C-C stretching vibrations \\
1220 & Ph-O-Ph stretching of aromatic ether chain \\
& structure; $1: 2: 4$ substituted phenyl ring \\
834 & C-H out to plane deviational vibrations \\
754 & Vibration of aromatic C-H \\
696 & C-S bond \\
545 & Bending of C-H \\
$1176 ; 1109 ; 1027$ & O=S=O stretching vibrations \\
968 & aromatic sulfonic acid \\
\hline
\end{tabular}

corresponding to carbonyl groups in both spectra exclude the presence of quinone moieties and support the formation of only polyether compounds during the electropolymerization.

\subsection{Proton conductivity of polymer films}

Fig. 7 shows Nyquist plots before (a) and after (b) electropolymerization of sulfonated phenol on stainless steel substrates. Both plots can be simulated using a $R_{\mathrm{el}}\left(Q R_{\mathrm{ct}}\right)$ equivalent circuit model, where $R_{\mathrm{el}}$ is the resistance of the polymer, $R_{\mathrm{ct}}$ is the charge transfer resistance and $Q$ a constant phase angle element, whose impedance $Z(Q)$ can be written:

$Z(Q)=\left(j \omega Y_{0}\right)^{-n}$

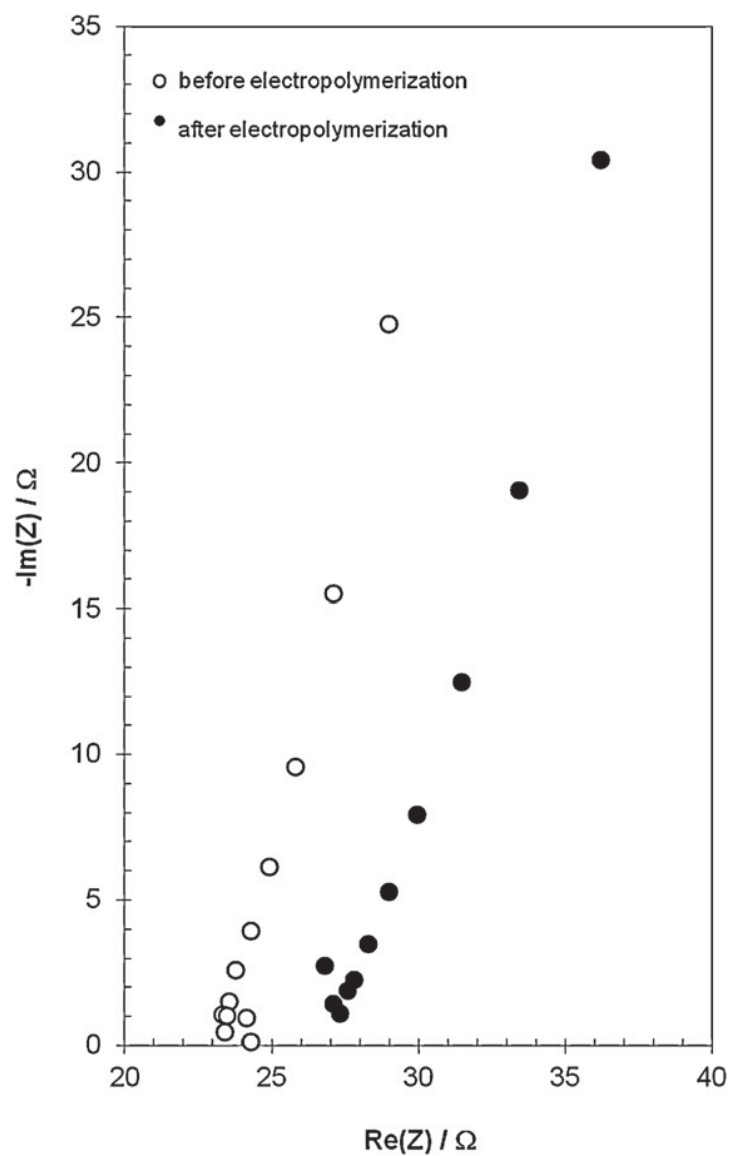

Fig. 7. Nyquist plots in the frequency range $10^{5}-10^{2} \mathrm{~Hz}$ before and after the electropolymerization of sulfonated phenol on a steel electrode. The electrode area was $0.28 \mathrm{~cm}^{2}$ 
Table 2

Electrical parameters from equivalent circuit fitting.

\begin{tabular}{lllll}
\hline Samples & $R_{\mathrm{el}}(\Omega)$ & $Y_{0}\left(\mathrm{~S} \mathrm{~s}^{-1}\right)$ & $n$ & $R_{\mathrm{ct}}(\Omega)$ \\
\hline Steel & 23.8 & $3.4 \times 10^{-5}$ & 0.90 & $2.38 \times 10^{4}$ \\
Steel + polymer & 26.6 & $9.5 \times 10^{-6}$ & 0.93 & $5.04 \times 10^{5}$ \\
\hline
\end{tabular}

In this equation, $\omega$ is the angular frequency and $n$ a characteristic exponent. The corresponding parameters of a typical experiment are listed in Table 2. The values of $n$ and $Y_{0}$ are consistent with interface capacities of metallic electrodes. The resistance $R_{\mathrm{el}}$ before electrodeposition is due to the electrolyte resistance $\left(\sigma\left(\mathrm{H}_{2} \mathrm{SO}_{4}\right.\right.$, $2 \%)=90 \mathrm{mS} / \mathrm{cm}$ ). The resistance of the polymer film with $20.9 \mu \mathrm{m}$ thickness is $2.8 \Omega$. According to the equation:

$\sigma=\frac{L}{\mathrm{R}_{\mathrm{el}} S}$

where $L$ is the thickness of the polymer and $S$ is the electrode area $\left(0.28 \mathrm{~cm}^{2}\right)$, the conductivity $(\sigma)$ of the polymer can be calculated to be $2.7 \mathrm{mS} / \mathrm{cm}$ at room temperature. The conductivity of polyphenyl oxide is in the order of $0.12 \mathrm{mS} / \mathrm{cm}$ [38]; the enhancement of conductivity is due to the presence of sulfonic acid groups in the material.The calculated proton conductivity in fully humidified conditions is in the same order of magnitude as those of other sulfonated aromatic polymers with similar degree of sulfonation, such as SPEEK [39] under these conditions. Further optimization is possible by increasing the average degree of sulfonation, which might be obtained by changing the sulfonation conditions, such as the use of stronger sulfonating agents.

\section{Conclusions}

Electropolymerization of sulfonated polyphenyl ether on steel substrates was for the first time performed and studied by CV or chronoamperometry. The functionalization of phenol with sulfonic acid groups was confirmed by NMR, EDX, and FTIR spectroscopy. The obtained sulfonated polyphenyl ether films have micrometer thickness and proton conductivity in the order of $3 \mathrm{mS} / \mathrm{cm}$ at room temperature. A higher conductivity might be obtained by higher degree of sulfonation of the polymer. Tests of other relevant properties, like gas permeability, will be necessary before proposing this material for fuel cell application.

\section{References}

[1] M.N. Yousaf, M. Mrksich, Journal of the American Chemical Society 121 (1999) 4286.

[2] M. Curreli, C. Li, Y. Sun, B. Lei, M.A. Gundersen, M.E. Thompson, C. Zhou, Journal of the American Chemical Society 127 (2005) 6922.
[3] Y.L. Bunimovich, G. Ge, K.C. Beverly, R.S. Ries, L. Hood, J.R. Heath, Langmuir 20 (2004) 10630.

[4] J.E. Dubois, P.-C. Lacaze, M.C. Pham, Journal of Electroanalytic Chemistry 117 (1981) 233.

[5] N.A. Kyeremateng, F. Dumur, P. Knauth, B. Pecquenard, T. Djenizian, Electrochemistry Communications 13 (2011) 894.

[6] D.D. Long, K.A. Marx, T. Zhou, Journal of Electroanalytic Chemistry 501 (2001) 107.

[7] G. Bereket, B.D. Duran, Progress in Organic Coatings 64 (2009) 57.

[8] N.B. Tahar, A. Savall, Elechtrochimica Acta 54 (2009) 4809.

[9] S. Andreescu, D. Andreescu, O.A. Sadik, Electrochemistry Communications 5 (2003) 681.

[10] P. Macech, J. Pemberton, Thin Solid Films 517 (2009) 5399.

[11] M.R. Mahmoudian, Y. Alias, W.J. Basirun, Materials Chemistry and Physics 124 (2010) 1022.

[12] A. Guenbour, A. Kacemi, A. Benbachir, Progress in Organic Coatings 39 (2000) 151.

[13] C. Berrios, R. Arce, M.C. Rezende, M.S. Ureta Zanartu, C. Gutierrez, Electrochimica Acta 53 (2008) 2768

[14] D.L. Franco, A.S. Afonso, S.N. Vieira, L.F. Ferreira, R.A. Goncalves, A.G. BritoMadurro, J.M. Madurro, Materials Chemistry and Physics 107 (2008) 404.

[15] N.B. Tahar, A. Savall, Electrochimica Acta 55 (2009) 465.

[16] J. Obirai, F. Bedioui, T. Nyokong, Journal of Electroanalytic Chemistry 576 (2005) 323.

[17] M. Pakula, M. Walczyk, S. Biniak, A. Swiatkowski, Chemosphere 69 (2007) 209.

[18] E.H. Zareie, B.K. Korbakti, A. Tanyolac, Journal of Hazardous Materials B87 (2001) 199.

[19] B. Vishnupriya, K. Ramya, K.S. Dhathathreyan, Journal Applied Polymer Science 83 (2002) 1792.

[20] Y. Liu, Q. Yu, J. Yuan, L. Ma, Y. Wu, European Polymer Journal 42 (2006) 2199.

[21] A.A. Argun, J.N. Ashcraft, P.T. Hammond, Advanced Materials 20 (2008) 1539

[22] L. Bao, R. Xiong, G. Wei, Electrochimica Acta 55 (2010) 4030.

[23] R. Lapeunte, F. Cases, P. Garces, E. Morallon, J.L. Vazques, Journal of Electroanalytic Chemistry 45 (1998) 163.

[24] A. Guenbour, A. Kacemi, A. Benbachir, L. Aries, Progress in Organic Coatings 38 (2000) 121.

[25] Y. Samet, D. Kraiem, R. Abdelhdi, Progress in Organic Coatings 69 (2010) 335.

[26] F. Bruno, M.C. Pham, J.E. Dubois, Electrochimica Acta 22 (1977) 451.

[27] G. Mengoli, M.M. Musiani, Progress in Organic Coatings 24 (1994) 237

[28] M. Khayet, J.P.G. Villaluenga, M.P. Godino, J.I. Mengual, B. Seoane, K.C. Khulbe, T. Matsuura, Journal of Colloid Interface Science 278 (2004) 410.

[29] J.G. Wijmans, H.J.J. Rutten, C.A. Smolders, Journal of Polymer Science Polymer Physics 23 (1985) 1941.

[30] D. Lu, W. Lu, C. Li, J. Liu, R. Guan, Polymer Bulletin 58 (2007) 673.

[31] S. Feng, Y. Shang, X. Xie, Y. Wang, J. Xu, Journal of Membrane Science 334 (2009) 13.

[32] K.T. Park, J.H. Chun, S.G. Kim, B.H. Chun, S.H. Kim, International Journal of Hydrogen Energy 36 (2011) 1813.

[33] M.L. Di Vona, D. Marani, A. D’Epifanio, E. Traversa, M. Trombetta, S. Licoccia, Polymer 46 (2005) 1754

[34] T. Yamase, M.T. Pope, Polyoxometalate Chemistry for Nano-composite Design, Kluwer Academic/Plenum Publishers, New York, 2002.

[35] S. Zhong, C. Liu, Z. Dou, X. Li, C. Zhao, T. Fu, H. Na, Journal of Membrane Science 285 (2006) 404.

[36] M.L. Di Vona, E. Sgreccia, M. Tamilvanan, M. Khadhraoui, C. Chassigneux, P. Knauth, Journal of Membrane Science 354 (2010) 134.

[37] L.V. Panteleeva, O.M. Tsyguleva, I.P. Krainov, L.L. Ostis, Journal of Applied Spectroscopy 62 (1995) 72.

[38] C. Chen, S. Mu, Chinese Journal of Polymer Science 20 (2002) 309.

[39] S. Kaliaguine, S.D. Mikhailenko, K.P. Wang, P. Xing, G. Robertson, M. Guiver, Catalysis Today 82 (2003) 213. 